\title{
Effect of Compressive Strength on $\gamma$-Radiation Attenuation Coefficients for High Performance Concrete
}

\author{
Mohammed M. Al-Humaiqani, Ahmed B. Shuraim, and Raja Rizwan Hussain
}

\begin{abstract}
An experimental investigation of radiation shielding properties of high performance concretes (HPCs) was mad under effect of different variables. HPCs were produced from different normal and heavyweight aggregate with three low water-to-cementitious materials ratios $(w / c m)$ to obtain different compressive strengths. The linear attenuation coefficients were measured at $0.663 \mathrm{MeV} \gamma$-rays energy of ${ }^{137} \mathrm{Cs}$ radioactive using $\mathrm{NaI}$ ( $\mathrm{Tl})$ scintillation detector. It was found that the compressive strength of heavyweight HPCs plays an important role in enhancing the attenuation of $\gamma$-rays. The compressive strength and attenuation of $\gamma$-rays have a near to linear relation. While in the normal concrete, the strength has no effect on the attenuation of $\gamma$-radiation. The mass attenuation coefficients were also compared with the values obtained by the United States National Institute of Standards and Technology (NIST). The comparison showed a reasonable agreement. It was observed that the attenuation of $\gamma$-rays is considerably affected by concrete density.
\end{abstract}

Index Terms-High performance concrete, $\gamma$-attenuation coefficients, aggregate types, compressive strength, water-to-cementatious materials ratio.

\section{INTRODUCTION}

High performance concrete (HPCs) is a concrete meeting special combinations of performance and uniformity requirements that cannot be achieved routinely using conventional constituents and normal mixing, placing, and curing practices as per ACI [1]. It can be produced from normal and heavy weight aggregates with or without supplementary cementitious materials (SCM). The material properties of high performance concrete (HPC) directly affect the design and construction of HPC structural members Therefore the selection of aggregates must be done carefully and closer control of aggregate quality with respect to grading and maximum size is necessary [2]. One of the HPCs is heavyweight concrete. It is defined as concrete with unit weight ranging from 2900 to $6000 \mathrm{~kg} / \mathrm{m}^{3}$ while unit weight of normal weight concrete varied between 2200 and $2450 \mathrm{~kg} / \mathrm{m}^{3}$ [3]-[5]. According to PCA [6], HPCs almost always has a higher strength than normal concrete.

In the nuclear power plants, medical units, and in structures where radioactive impermeability is required, the concrete is used widely as radiation shielding material because of its low price and good shielding performance. Heavyweight concrete is used principally for radiation

Manuscript received April 6, 2013; revised May 28, 2013. This research is supported by the National Plan for Science and Technology at King Saud University, Project No. 08-ADV208-02.

The authors are with Civil Engineering Department, College of Engineering, King Saud University, Riyadh, Saudi Arabia (e-mail: alhumaiqani@hotmail.com; ashuraim@gmail.com; raja386@hotmail.com). shielding for the prevention of seepage from radioactive structures and protects against the harmful effects of X-rays, $\gamma$-rays...etc. [6], [7]. Overall, heavyweight concrete has been used where it is necessary to reduce the thickness of radiation shielding, generally because of space considerations [8]-[13]. According to Lee, et al. [14] the aggregate of concrete plays an essential role in modifying physical-mechanical properties of concrete; it also affect significantly shielding properties of concrete [2], [6], [15]. In general, a number of theoretical and experimental studies have been conducted on heavy concretes [16]-[21].

Reference [9] measured the attenuation coefficients of $\gamma$ rays of 12 concrete samples with and without supplementary cementitious materials, at energies of 59.5 and $661 \mathrm{keV}$. Reference [8] shows that the linear attenuation coefficients $(\mu)$ decrease with the increasing the photon energy for their concretes and the linear attenuation coefficient depends on photoelectric effect and Compton scattering at this energy. It was concluded that barite was effective at $0.663 \mathrm{keV}$.

Enormous work regarding linear and mass attenuation coefficients is available in the literature. Nevertheless, the effect of the strength of HPC with the use of lower water-to-cementitious materials ratios $(\mathrm{w} / \mathrm{cm})$, supplementary cementitious materials (SCM) and heavy weight aggregate together on gamma shielding properties is still limited. Therefore, this investigation aims at production of different types of normal and heavy HPC from different materials in order to calculate the linear and mass attenuation coefficients for each in terms of effect of the HPCs compressive strength as one of the main mechanical properties of the concrete.

In this paper, the radiation transmission measurement has been conducted for normal and heavy HPC carried out with different low w/cm ratios (0.30-0.4) for $0.663 \mathrm{MeV}$ energy of ${ }^{137} \mathrm{Cs}$ radioactive isotope by using $\mathrm{NaI}(\mathrm{Tl})$ scintillation detector and linear and mass attenuation coefficients were calculated. All the results were compared with previous research and X-ray mass attenuation coefficient values of NIST [22]. In addition, the effect of the compressive strength on the attenuation of $\gamma$-rays also was investigated.

\section{EXPERIMENTATION}

\section{A. Materials and Methods}

This section contains the material properties of HPC ingredients, mix design as per ACI 211.4R [23] and procedures for strength of HPC. Type I ordinary Portland cement from Yammama cement plant located in Riyadh in compliance with the requirements of ASTM C150 [24] has been used. Micro silica with specific gravity of 2.27 is the 
mineral admixture was used in this investigation for all the mixtures. Chemical composition and Physical characteristics of micro-silica used in this research met the requirements of ASTM C1240 [25].

The water-to-cementitious materials ratio $(\mathrm{w} / \mathrm{cm})$ was varied from $0.30-0.40$ for the experimental program so that the effect of compressive strength can be investigated deeply under the influence of different water to cementitious materials ratios. A high performance concrete superplasticiser (Glenium 51) based on modified polycarboxylic ether was employed as chemical admixture having relative specific gravity of 1.1 to make the HPC workable [26]. Five types of coarse aggregates (designated as 'RY', 'MK', 'AB', 'BR' and 'HM') and two sources of fine aggregate (designated as ' $\mathrm{RN}$ ' and ' $\mathrm{CR}$ ') with micro-silica (designated as ' $\mathrm{S}$ ') were investigated in this paper.

The three normal weight coarse aggregates were taken from three different sources of Saudi Arabia, namely Riyadh Makkah and Abha located far apart from each other. The remaining two types of coarse aggregate 'BR' and ' $\mathrm{HM}$ ' are of heavy weight in nature and were imported from Belgium for the research under consideration.

The maximum particle size of normal coarse aggregate was kept constant at $20 \mathrm{~mm}$ in all normal HPC mixtures. It was also separated into two size fractions, $5-10 \mathrm{~mm}$ and $10-20 \mathrm{~mm}$. Hematite and barite were varied between 20 and $25 \mathrm{~mm}$ and their fractions were $0-25$ and $0-20 \mathrm{~mm}$ respectively.

The two normal weight fine aggregates were also taken from two different parts of Riyadh city. Aggregate ' $\mathrm{RN}$ ' is natural and has whitish color with size of $0-3 \mathrm{~mm}$. The second type of fine aggregate named ' $\mathrm{CR}$ ' in this paper is $3-5 \mathrm{~mm}$ in size and also whitish in color produced by crushing the sedimentary stones. It is used in mix with RN sand to obtain finesses modulus of the fine materials in compliance with ASTM requirements [27]. The physical properties of HPC ingredients used in this paper were determined according to ASTM C33 [27] standards are given in Table I.

\begin{tabular}{|c|c|c|c|c|c|}
\hline Aggregate & $\begin{array}{l}\text { Relative } \\
\text { specific } \\
\text { gravity }\end{array}$ & $\begin{array}{l}\text { Water } \\
\text { absorptio } \\
\text { n capacity } \\
(\text { mass } \%)\end{array}$ & $\begin{array}{l}\text { Unit } \\
\text { weight } \\
\left(\mathrm{kg} / \mathrm{m}^{3}\right)\end{array}$ & $\begin{array}{l}\text { Voids } \\
(\%)\end{array}$ & $\begin{array}{l}\text { Moisture } \\
\text { content } \\
(\%)\end{array}$ \\
\hline CR $(3-5 \mathrm{~mm})$ & 2.60 & 1.43 & 1604 & 38.06 & 0.55 \\
\hline $\mathrm{RN}(0-3 \mathrm{~mm})$ & 2.60 & 0.93 & 1720 & 33.89 & 0.15 \\
\hline $\begin{array}{l}\mathrm{RY} \\
\mathrm{mm})\end{array}$ & 2.61 & 1.10 & 1550 & 39.83 & 0.32 \\
\hline $\begin{array}{l}\mathrm{RY} \\
\mathrm{mm})\end{array}$ & 2.62 & 1.30 & 1575 & 38.87 & 0.59 \\
\hline $\begin{array}{l}\mathrm{MK} \quad(10-20 \\
\mathrm{mm})\end{array}$ & 2.70 & 1.15 & 1681 & 36.86 & 0.49 \\
\hline $\begin{array}{l}\mathrm{MK} \\
\mathrm{mm})\end{array}$ & 2.73 & 1.55 & 1683 & 42.53 & 0.36 \\
\hline $\begin{array}{l}\mathrm{AB} \\
\mathrm{mm})\end{array}$ & 2.77 & 0.85 & 1623 & 40.74 & 0.17 \\
\hline $\mathrm{AB}(5-10 \mathrm{~mm})$ & 2.76 & 1.82 & 1683 & 37.87 & 0.32 \\
\hline $\mathrm{BR}(0-25 \mathrm{~mm})$ & 4.06 & 0.65 & 3020 & 25.00 & 0.13 \\
\hline $\mathrm{HM}(0-20 \mathrm{~mm})$ & 4.67 & 1.36 & 3326 & 27.65 & 0.10 \\
\hline
\end{tabular}

Three different series of HPC named as CS-1, 2 and 3 have been made using three low w/cm of $0.30,0.35$ and 0.40 respectively. Each series consisted of three normal and two heavy HPC produced from RY, MK and $\mathrm{AB}$ normal aggregates and $\mathrm{BR}$ and $\mathrm{HM}$ as heavy aggregates respectively. For each series of mixtures, cementitious materials quantity and water-to-cementitious ratio was kept constant and five mixtures made. For $\mathrm{w} / \mathrm{cm}$ of $0.3,0.35$ and 0.40 , the cementitious materials quantity was $500,450,400 \mathrm{~kg} / \mathrm{m}^{3}$ respectively. $10 \%$ micro-silica was used as cement replacement. The three series of mixtures were named as CS-1: $\quad$ RY/MK/AB/BR/HM-W30-S10, $\quad$ CS-2: $\mathrm{RY} / \mathrm{MK} / \mathrm{AB} / \mathrm{BR} / \mathrm{HM}-\mathrm{W} 35-\mathrm{S} 10$ and CS-3: $\mathrm{RY} / \mathrm{MK} / \mathrm{AB} / \mathrm{BR} / \mathrm{HM}-\mathrm{W} 40-\mathrm{S} 10$. Proportions of all mixtures ingredients used in this study were designated with ACI-211.4R [23] and given in the Table II (a), (b) and (c).

TABLE II: MIX PROPORTIONS OF HPC MIXTURES (A) CS-1

\begin{tabular}{llllll}
\hline \hline & \multicolumn{7}{l}{ Unit weight $\left(\mathrm{kg} / \mathrm{m}^{3}\right)$} & & \\
\cline { 2 - 6 } Component & RY-W30 & MK-W & AB-W & BR-W & HM-W \\
& $-S 10$ & $30-S 10$ & $30-S 10$ & $30-S 10$ & $30-S 10$ \\
\hline \hline Cement & 450 & 450 & 450 & 450 & 450 \\
Micro-silica & 50 & 50 & 50 & 50 & 50 \\
Water & 161.19 & 165.24 & 167.83 & 160.91 & 186.98 \\
FA (CR-Sand) & 240.04 & 228.81 & 238.58 & - & - \\
FA (RN-Sand) & 445.80 & 424.93 & 443.08 & - & - \\
RY (5-10 mm) & 739.02 & - & - & - & - \\
RY $(10-20 \mathrm{~mm})$ & 316.72 & - & - & - & - \\
MK $(5-10 \mathrm{~mm})$ & - & 792.02 & - & - & - \\
MK $(10-20 \mathrm{~mm})$ & - & 339.62 & - & - & - \\
AB (5-10 mm) & - & - & 783.25 & - & - \\
AB (10-20 mm) & - & - & 335.68 & - & - \\
BR (0-25 mm) & - & - & - & 2706.9 & - \\
HM $(0-20 \mathrm{~mm})$ & - & - & - & - & 3004.7 \\
Admixtures & 4.125 & 3.190 & 3.135 & 8.250 & 5.225 \\
GL-51 & & & & & \\
\hline \hline
\end{tabular}

(B) $\mathrm{CS}-2$

\begin{tabular}{|c|c|c|c|c|c|}
\hline \multirow[b]{2}{*}{ Component } & \multicolumn{5}{|c|}{ Unit weight $\left(\mathrm{kg} / \mathrm{m}^{3}\right)$} \\
\hline & $\begin{array}{l}\text { RY-W } \\
35-S 10\end{array}$ & $\begin{array}{l}\text { MK-W } \\
35-S 10\end{array}$ & $\begin{array}{l}\text { AB-W } \\
35-S 10\end{array}$ & $\begin{array}{l}\text { BR-W } \\
35-S 10\end{array}$ & $\begin{array}{l}\mathrm{HM}-\mathrm{W} \\
35-\mathrm{S} 10\end{array}$ \\
\hline Cement & 405 & 405 & 405 & 405 & 405 \\
\hline Micro-silica & 45 & 45 & 45 & 45 & 45 \\
\hline Water & 169.39 & 173.14 & 175.66 & 169.10 & 195.53 \\
\hline FA (CR-Sand) & 249.52 & 237.62 & 247.22 & - & - \\
\hline FA (RN-Sand) & 463.39 & 441.30 & 459.13 & - & - \\
\hline $\mathrm{RY}(5-10 \mathrm{~mm})$ & 739.02 & - & - & - & - \\
\hline $\mathrm{RY}(10-20 \mathrm{~mm})$ & 316.72 & - & - & - & - \\
\hline $\mathrm{MK}(5-10 \mathrm{~mm})$ & - & 792.44 & - & - & - \\
\hline MK (10-20 mm) & - & 339.62 & - & - & - \\
\hline $\mathrm{AB}(5-10 \mathrm{~mm})$ & - & - & 783.25 & - & - \\
\hline $\mathrm{AB}(10-20 \mathrm{~mm})$ & - & - & 335.68 & - & - \\
\hline $\mathrm{BR}(0-25 \mathrm{~mm})$ & - & - & - & 2745.4 & - \\
\hline $\mathrm{HM}(0-20 \mathrm{~mm})$ & - & - & - & - & 3047.1 \\
\hline $\begin{array}{l}\text { Admixtures } \\
\text { GL-51 }\end{array}$ & 2.475 & 2.340 & 2.475 & 6.300 & 3.600 \\
\hline \multicolumn{6}{|c|}{ (C) $\mathrm{CS}-3$} \\
\hline \multirow[b]{2}{*}{ Component } & \multicolumn{5}{|c|}{ Unit weight $\left(\mathrm{kg} / \mathrm{m}^{3}\right)$} \\
\hline & $\begin{array}{l}\text { RY-W40- } \\
\text { S10 }\end{array}$ & $\begin{array}{l}\text { MK-W } \\
40-\mathrm{S} 10 \\
\end{array}$ & $\begin{array}{l}\text { AB-W } \\
40-S 10 \\
\end{array}$ & $\begin{array}{l}\text { BR-W } \\
40-S 10 \\
\end{array}$ & $\begin{array}{l}\text { HM-W } \\
40-S 10 \\
\end{array}$ \\
\hline Cement & 360 & 360 & 360 & 360 & 360 \\
\hline Micro-silica & 40 & 40 & 40 & 40 & 40 \\
\hline Water & 172.41 & 176.15 & 178.84 & 172.69 & 199.22 \\
\hline FA (CR-Sand) & 262.98 & 251.07 & 261.05 & - & - \\
\hline FA (RN-Sand) & 488.39 & 466.27 & 484.81 & - & - \\
\hline $\mathrm{RY}(5-10 \mathrm{~mm})$ & 739.02 & - & - & - & - \\
\hline $\mathrm{RY}(10-20 \mathrm{~mm})$ & 316.72 & - & - & - & - \\
\hline $\mathrm{MK}(5-10 \mathrm{~mm})$ & - & 792.44 & - & - & - \\
\hline $\mathrm{MK}(10-20 \mathrm{~mm})$ & - & 339.62 & - & - & - \\
\hline $\mathrm{AB}(5-10 \mathrm{~mm})$ & - & - & 783.25 & - & - \\
\hline $\mathrm{AB}(10-20 \mathrm{~mm})$ & - & - & 335.68 & - & - \\
\hline $\mathrm{BR}(0-25 \mathrm{~mm})$ & - & - & - & 2805.5 & - \\
\hline $\mathrm{HM}(0-20 \mathrm{~mm})$ & - & - & - & - & 3110.6 \\
\hline $\begin{array}{l}\text { Admixtures } \\
\text { GL-51 }\end{array}$ & 1.880 & 1.760 & 1.480 & 4.400 & 2.800 \\
\hline
\end{tabular}


All mixtures were prepared in a rotary planetary mixer with capacity of $180 \mathrm{~L}$. To determine whether the target slump has been reached, the slump test was performed as per ASTM C143 [28]. In this study, the slump of all concrete mixtures ranged between 150 and $200 \mathrm{~mm}$. After the mixing procedure was completed, the concrete was cast in standard $150 \mathrm{~mm}$ cubic and plastic cylinders of size $150 \varphi$ x $300 \mathrm{~mm}$ as per ASTM C496 [26]. From each HPC mixture, several $150 \mathrm{~mm}$ cubic concrete specimens for radiation test. The standard cylinders of $150 \mathrm{~mm} \varphi \times 300 \mathrm{~mm}$ height to run the compressive strength test were also produced. The specimens in the molds were stored in the laboratory environment at standard room temperature for the first $24 \mathrm{~h}$ followed by de-molding and then water cured under standard conditions until the age of testing.

\section{B. Testing Method and Procedure}

\section{1) Radiation setup and Apparatus}

The arrangement of experimental set up and test block diagram describing all the parts of the measuring system used in the test are shown in Fig. 1. The radioactive source used in this study to carry out radiation tests was ${ }^{137} \mathrm{Cs}$ with energy of $0.663 \mathrm{MeV}$. NaI(Tl) scintillation detector housed in a $16 \mathrm{~mm}$ thick lead jacket with a $5 \mathrm{~mm}$ diameter holed collimator has been used to measure the intensities of $\gamma$-rays. The attenuation coefficients for $\gamma$-ray of ${ }^{137} \mathrm{Cs}$ source was calculated from equation 1 [29] and measured using narrow beam experimental setup.

$$
I=I_{0} e^{-\mu x}
$$

where, $\mu$ is gamma-ray linear attenuation coefficient; $I_{0}$ is the intensity of first measurement without specimen; $I$ is the intensity passing the specimen and $x$ is the thickness of the specimen. The total mass attenuation coefficients, $\mu_{m}$, are also given as follows:

$$
\mu_{m}=\frac{\mu}{\rho}=\left(\frac{1}{x}\right) \ln \left(\frac{I_{0}}{I}\right) / \rho\left(\mathrm{cm}^{2} / \mathrm{g}\right)
$$

where, $\rho$ is the density of the sample.

Using the digital counter, the incident gamma beam with the intensity of $I_{0}$ applied perpendicularly without specimen was measured. After that, the measuring of the intensities of gamma beam $I$ passed the HPC specimens were computed. In this study, the counts $I_{0}$ and $I$ were measured carried out on $150 \mathrm{~mm}$ cubic HPC specimens for each mixture at the same time and under the same experimental and environmental conditions avoiding any inconsistency. From these measurements, the calculations of linear $(\mu)$ and total mass attenuation $\left(\mu_{m}\right)$ coefficients were computed by means of Eq. 1 and 2 respectively.

\section{2) Test of compressive strength}

At the age of testing, the specimens were taken out from the curing tank and were end capped with a capping compound material. The compression test is conducted on the hardened concrete cylinders as prescribed by ASTM C 39 [30].

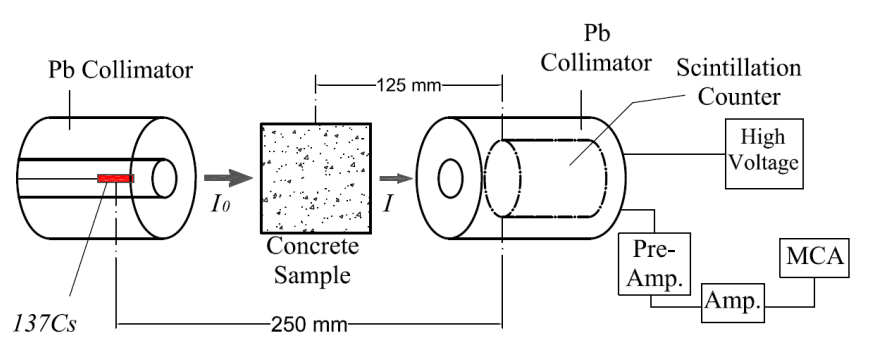

Fig. 1. Experimental setup for gamma radioactive test

\section{Results AND Discussions}

The linear and mass attenuation coefficients $(\mu)$ for all the three HPC series were measured at photon energy of 0.663 $\mathrm{MeV}$ and compared with the results which available in the literature [8], [9], [15]-[17], [22], [31]. The measured results are listed in Table III.

TABLE III: UNIT WEIGHT, LINEAR AND MASS ATTENUATION COEFFICIENTS

\begin{tabular}{|c|c|c|c|c|c|}
\hline \multirow{4}{*}{$\begin{array}{l}\text { HPCs } \\
\text { Series }\end{array}$} & \multirow{4}{*}{ Mix Ref. } & \multirow{4}{*}{$\begin{array}{l}\text { Unit } \\
\text { weight } \\
(\mathrm{gm} / \mathrm{c} \\
\left.\mathrm{m}^{3}\right)\end{array}$} & \multirow{4}{*}{$\begin{array}{l}\begin{array}{l}\text { Linear } \\
\text { atten. } \\
\text { coef. } \\
\left(\mathrm{cm}^{-1}\right)\end{array} \\
0.663 \\
\mathrm{MeV}\end{array}$} & \multicolumn{2}{|c|}{$\begin{array}{l}\text { Mass attenuation } \\
\text { coef. }\left(\mathrm{cm}^{2} / \mathrm{g}\right)\end{array}$} \\
\hline & & & & $\begin{array}{l}\text { This } \\
\text { research }\end{array}$ & $\begin{array}{l}\text { NIST } \\
\text { results }\end{array}$ \\
\hline & & & & 0.663 & 0.600 \\
\hline & & & & $\mathrm{MeV}$ & $\mathrm{MeV}$ \\
\hline \multirow{5}{*}{ CS-1 } & RY-W30-S10 & 2.407 & 0.1672 & 0.0695 & \multirow[t]{3}{*}{0.0824} \\
\hline & MK-W30-S10 & 2.454 & 0.1698 & 0.0692 & \\
\hline & AB-W30-S10 & 2.472 & 0.1788 & 0.0723 & \\
\hline & BR-W30-S10 & 3.376 & 0.2519 & 0.0746 & \multirow[t]{2}{*}{0.0825} \\
\hline & HM-W30-S10 & 3.697 & 0.2661 & 0.0720 & \\
\hline \multirow{5}{*}{$\mathrm{CS}-2$} & RY-W35-S10 & 2.391 & 0.1622 & 0.0678 & \multirow[t]{3}{*}{0.0824} \\
\hline & MK-W35-S10 & 2.437 & 0.1696 & 0.0696 & \\
\hline & AB-W35-S10 & 2.454 & 0.1764 & 0.0719 & \\
\hline & BR-W35-S10 & 3.372 & 0.2446 & 0.0725 & \multirow[t]{2}{*}{0.0825} \\
\hline & HM-W35-S10 & 3.697 & 0.2578 & 0.0697 & \\
\hline \multirow{5}{*}{$\mathrm{CS}-3$} & RY-W40-S10 & 2.382 & 0.1653 & 0.0694 & \multirow[t]{2}{*}{0.0824} \\
\hline & MK-W40-S10 & 2.428 & 0.1709 & 0.0704 & \\
\hline & AB-W40-S10 & 2.445 & 0.1775 & 0.0726 & \multirow{3}{*}{0.0825} \\
\hline & BR-W40-S10 & 3.383 & 0.2369 & 0.0700 & \\
\hline & HM-W40-S10 & 3.713 & 0.2473 & 0.0660 & \\
\hline
\end{tabular}
AT 0.663 MEV T-RAYS OF HPC SERIES TESTED IN LAB CONDITIONS

It can be seen that the highest mass attenuation coefficient values at $0.663 \mathrm{MeV} \gamma$-ray energy obtained from heavy HPCs (BR and HM) and they are close to X-ray mass attenuation coefficient values of NIST [22]. The mass attenuation coefficient value of the barite concrete (BR-W30-S10) is $0.0746 \mathrm{~cm}^{2} / \mathrm{g}$ at $0.663 \mathrm{MeV} \gamma$-ray energy and the value of NIST is 0.0825 at $0.600 \mathrm{MeV}$. Among all normal HPCs, the HPC containing 'AB' aggregate obtained the highest density and highest mass attenuation values. It has also a good agreement with the values obtained by NIST for ordinary concrete. The attenuation coefficients obtained in this paper from all concrete series: normal, heavy and complete set of HPCs are plotted in Figs. 2(a), (b) and (c) respectively. It can be seen that the highest attenuation coefficients are obtained from the HPC samples produced in the first series (CS-1) for each mixture individually. While the lowest values were calculated in CS-3 samples, as shown in Fig. 2(c). The difference is very low in case of normal HPCs (Fig. 2(a)). However, it is considerable in case of heavyweight HPCs and reached 8-10\% more as shown in Fig. 2(b). 
It is observed that the attenuation of $\gamma$-rays in normal and heavy HPCs is considerably affected by the concrete density, this is consistent with the previous literature [8], [11], [14], [32]-[34]. With a little increase in density, a significant increase in the attenuation coefficients was observed as shown in Fig. 3(a), (b) and (c). It is seen in this paper that when the density of the normal and heavy high performance concrete increases, the $\gamma$-attenuation coefficients increases with the same percent as shown in Fig. 3(c). However, it is seen from Fig. 3(c) that the relation between HPC density and attenuation of $\gamma$-rays approximately is linear. Among the normal HPCs, concrete 'AB' has the highest density due to the specific gravity of the coarse aggregate and is the best normal HPC for shielding purposes in this paper as it obtained the highest attenuation values. Its values are 5 and 3 percent higher than those obtained with concretes ' $R Y$ ' and 'MK' respectively.

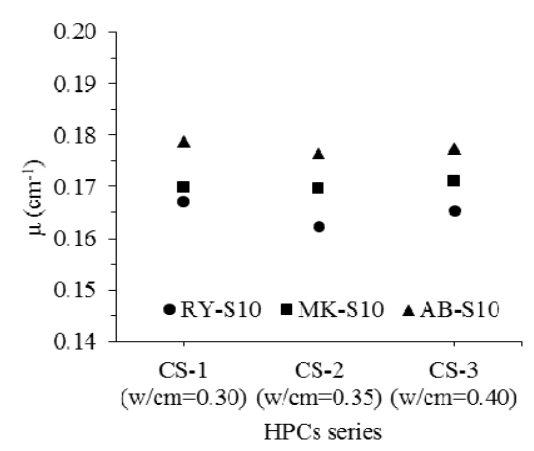

(a) Normal HPCs

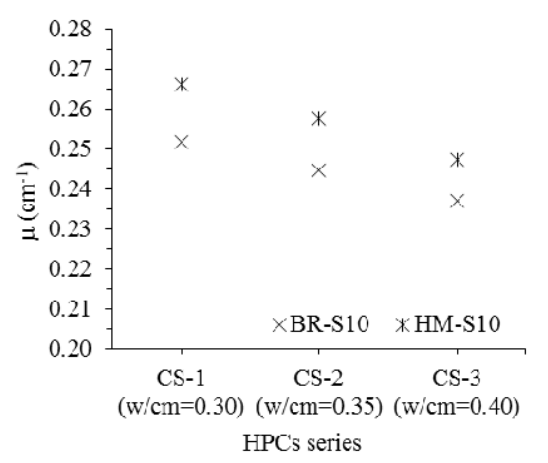

(b) Heavy HPCs

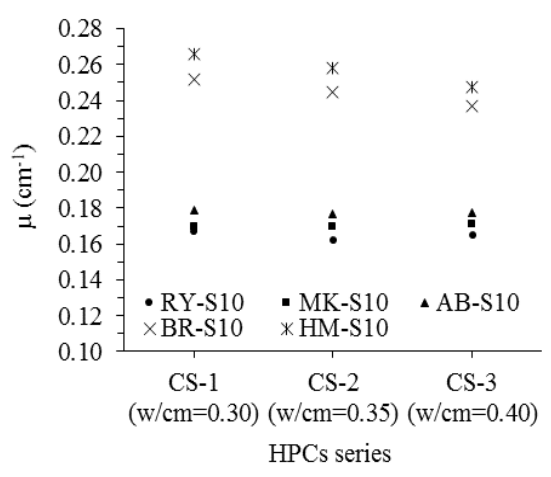

(c) Normal and heavy HPCs

Fig. 2. Linear attenuation coefficients of $\gamma$-rays measured at $0.663 \mathrm{MeV}$ $\gamma$-rays

Generally, the unit weight of normal concrete varies between 2200 and $2450 \mathrm{~kg} / \mathrm{m}^{3}$ [4]-[5]. In this study, normal HPCs were produced with unit weights ranges between 2382 to $2472 \mathrm{~kg} / \mathrm{m}^{3}$. It can be said that these values is important for nuclear radiation structures. It was found that even a little increase in the concrete unit weight positively affect the attenuation of $\gamma$-rays. Therefore, the production of normal HPCs using normal materials with higher specific gravity is recommended. However, it must be noted that the density often does not have a unique value but depends on the physical state of the material [5]. Therefore, care must be taken during the selection of sensitive worth density for special structures such as nuclear containment structural facilities (NCSFs).

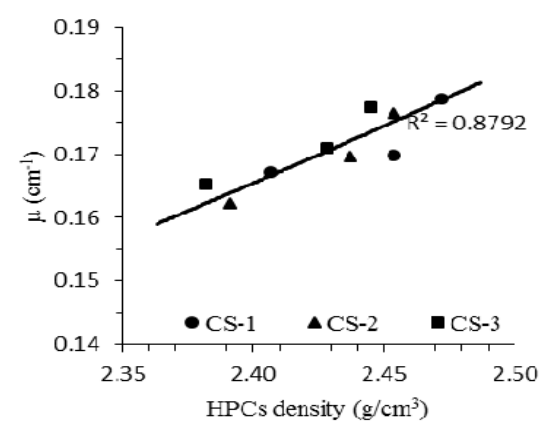

(a) Normal HPCs

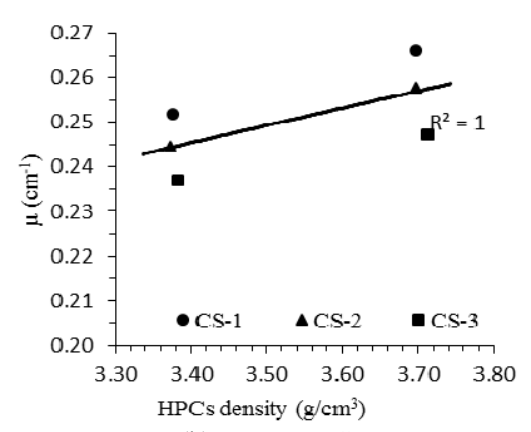

(b) Heavy HPCs

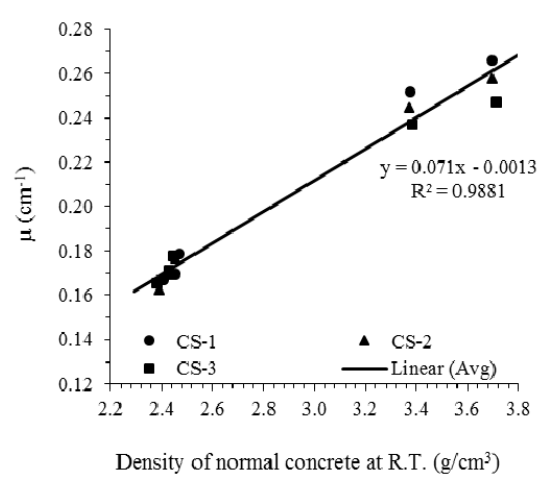

(c) Normal and heavy HPCs

Fig. 3. Linear attenuation coefficients versus density of normal and heavy HPCs at $0.663 \mathrm{MeV} \gamma$-rays

TABLE IV: \%AGE OF COMPRESSIVE STRENGTH OF HPCS AT DIFFERENT W/CM RATIOS

\begin{tabular}{lccc}
\hline \multicolumn{4}{c}{ W/CM RATIOS } \\
\hline \hline HPCs & $(\mathrm{CS}-1)$ & $(\mathrm{CS}-2)$ & $(\mathrm{CS}-3)$ \\
\hline \hline Normal & 1 & 0.81 & 0.74 \\
Heavy & 1 & 0.97 & 0.92 \\
\hline \hline
\end{tabular}

The compressive strength of HPCs is the mechanical property, which targeted in this paper to be studied in terms of its effect on the shielding properties. High compressive strength was a result of the HPCs mix design using three different low water-to-cementitious materials ratios 0.30 , 0.35 and 0.40 . The normal and heavy HPCs that produced in 
this paper obtained high compressive strength. This compressive strength ranged between 54 and $96 \mathrm{MPa}$ for normal HPCs and it was between 57 and 92 for heavy concretes. These values of strength have a good agreement with the curve developed by Aitcin [2] for compressive strength versus proposed $\mathrm{w} / \mathrm{cm}$. The strength development can be seen in Fig. 4(a) and (b) versus w/cm ratios for normal and Heavy HPCs respectively. The values of strength of normal and heavy HPCs obtained in the three series with the three different low w/cm ratios used in this paper is shown in Table IV.

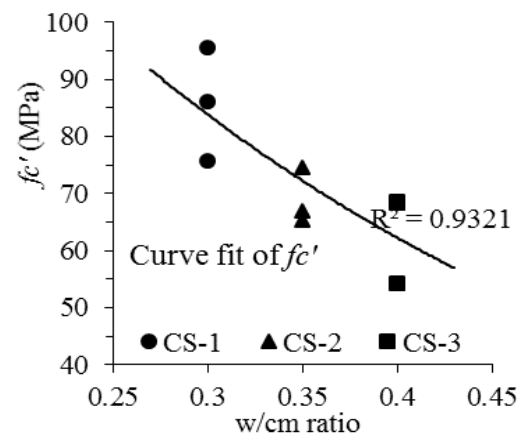

(a) Normal HPCs

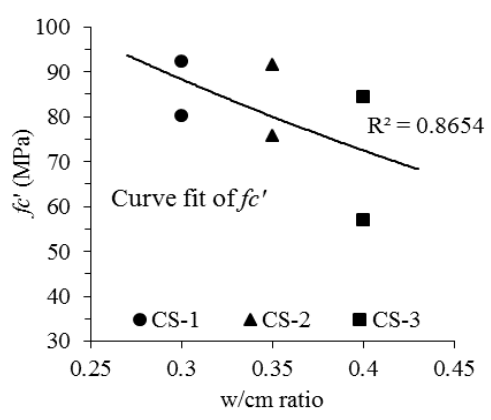

(b) Heavy HPCs

Fig. 4. Normal and heavy HPCs compressive strengths $\left(f c^{\prime}\right)$ versus different low $\mathrm{w} / \mathrm{cm}$ ratios

It can be seen that the concrete 'RY' and 'HM' obtained the highest strength of 96 and $92 \mathrm{MPa}$ respectively with concrete ' $\mathrm{AB}$ ' of CS-1 giving the lowest value (76 MPa). The third series (CS-3) shows the lowest strength values of normal and heavy HPCs compared to those produced in the two other series. Their strength values were ranged between 54 and $84 \mathrm{MPa}$. Nevertheless, the biggest variation appeared between the same concrete types in the three series (different $\mathrm{w} / \mathrm{cm}$ ratios). It was noted that the strength increases with low $\mathrm{w} / \mathrm{cm}$ ratio as expected. The maximum strength variations in each normal HPCs ' $R Y$ ', 'MK' and 'AB' is about 28 percent from CS-1 to 3. But, it is low in the heavy HPCs ' $\mathrm{HM}$ ' amounting to about 8 percent. Overall, although big variations in the strength of normal HPCs was observed but this variation does not affect the attenuation of $\gamma$-rays. The attenuation in all normal HPCs is not affected by the strength of the concrete. It is found that when the strength increases or decreases, the performance of the concrete to attenuate the radiation varies but not directly related to the strength.

In Fig. 5(a) and (b), the attenuation coefficients $\mu\left(\mathrm{cm}^{-1}\right)$ have been plotted versus the compressive strength $\left(f c^{\prime}\right)$ for normal and heavy HPCs. It was observed that the compressive strength $\left(f c^{\prime}\right)$ of normal HPCs produced using low $\mathrm{w} / \mathrm{cm}$ ratio has very small effect on the attenuation of $\gamma$-rays within a wide range of strength. Therefore, it can be noted that in the normal HPCs, the strength does not have significant effect on the shielding properties in closer range of $w / \mathrm{cm}$ ratios. It means that within the constraints of this paper, the compressive strength $\left(f_{c^{\prime}}\right)$ of the normal HPCs designed for shielding can be partially neglected up to some extent in calculations of shielding properties. This has also been represented by [5], [35]. Therefore, it can be suggested that the lowest strength which can meet the structural, mechanical and other requirements can be utilized where there are economic constraints. In general, it is speculated from the results of Fig. 4(a) that at higher $\mathrm{w} / \mathrm{cm}$ ratio such as 0.6 produces a normal concrete having lower strength range (30-35) and that may or may not affect the attenuation of the $\gamma$-rays. Further investigation on the effect of low concrete strength at high $\mathrm{w} / \mathrm{cm}$ ratios on the attenuation of $\gamma$-rays is recommended.

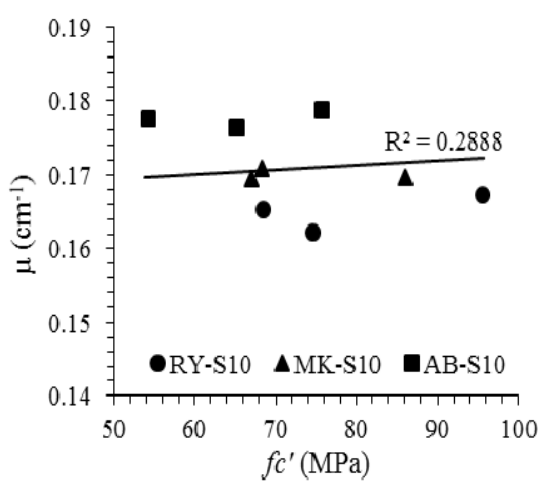

(a) Normal HPCs

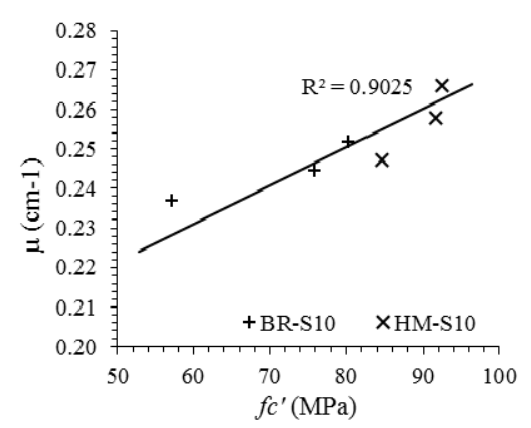

(b) Heavy HPCs

Fig. 5. Linear attenuation coefficients versus HPC compressive strengths

A further deep investigation for verification within a large range of $w / \mathrm{cm}$ ratios is still needed. However, the situation is different in heavy weight HPCs. The strength plays an important role in enhancing the attenuation of $\gamma$-rays as shown in Fig. 5 (b). The attenuation of $\gamma$-rays increases when the strength increases. It was found that when the compressive strength increases by 5 and $8 \%$, the attenuation coefficients increases by 4 and 7 percent respectively. The compressive strength and attenuation of $\gamma$-rays have a near to linear relation. That means the shielding properties of the heavy HPCs (BR and HM) is improved more when its strength becomes high. In this paper, the heavy weight HPCs in each series have the best linear attenuation coefficients and their gradual increase starts from CS-3 reaching the highest values at CS-1. It reflects a good HPC microstructure that effects on the photon radiation energy absorbent due to its linear correlation with concrete density at low $\mathrm{w} / \mathrm{cm}$ ratio [8]. It was observed that heavyweight HPC microstructure such at 
CS-1 with w/cm 0.30 was denser as compared to the others and 'BR' and ' $\mathrm{HM}$ ' concretes obtained attenuation of $\gamma$-rays 33-54 percent more than the normal concretes.

\section{CONCLUSIONS}

The effect of compressive strength of normal and heavy weight high performance concretes (HPCs) on the attenuation coefficients of $\gamma$-rays is experimentally investigated. The results were compared with results available in the literature. The comparisons showed a reasonable agreement along with significant findings. The following conclusions can be drawn:

- Heavy concrete compressive strength plays an important role in enhancing the attenuation of $\gamma$-rays. When the strength increases, the attenuation of $\gamma$-rays increases. The compressive strength and attenuation of $\gamma$-rays have a near to linear relation.

- Within the constraints of this paper, normal concrete showed that the compressive strength $\left(f c^{\prime}\right)$ has almost no significant effect on the shielding properties.

- The concrete density considerably affects the attenuation of $\gamma$-rays in HPCs. When the concrete density increases, the attenuation of $\gamma$-rays was noted.

- Hematite and barite heavy concretes obtained the higher attenuation coefficients and showed the best properties of shielding. This can be attributed to their high density and strength

- Among all the normal HPCs, concrete 'AB' showed the lowest value of compressive strength but it is more effective at $0.663 \mathrm{keV}$.

- The verification on the relation of strength and attenuation of $\gamma$-rays for normal high performance concrete within a large range of $\mathrm{w} / \mathrm{cm}$ ratios is still needed and remains as scope for future works.

\section{REFERENCES}

[1] H. G. Russell, "ACI defines High -performance concrete," Concrete International, vol. 21, pp. 56-57, 1999.

[2] P. C. Aitcin, High-Performance Concrete (Modern Concrete Technology), University of Sherbrooke, Quebec: Taylor \& Francis, Canada, 2004, ch. 7, pp. 162-211.

[3] T. Y. Erdogan, Concrete, METU Press, Ankara, Turkey, 2003, pp. 50-123.

[4] Concrete Construction Engineering Handbook, CRC Press, Florida, US, E. G. Nawy, 1997, pp. 1-17.

[5] M.F. Kaplan, Concrete Radiation Shielding; Longman Scientific and Technical, Longman Group UK Limited Essex England, 1989, pp. 80-198.

[6] PCA, Design and control of concrete mixtures, Portland Cement Association (PCA), 14th ed. Voice: 847.966.6200, 2003, ch. 17, pp. 300-313.

[7] I. B. Topcu, "Properties of heavyweight concrete produced with barite," Cement and Concrete Research, vol. 33, pp. 815-822, 2003.

[8] F. Demir, G. Budak, R. Sahin, A. Karabulut, M. Oltulu, and A. Und, "Determination of radiation attenuation coefficients of heavy weight and normal-weight concretes containing colemanite and barite for $0.663 \mathrm{MeV} \gamma$-rays" Annals of Nuclear Energy, vol. 38, pp. 1274-1278, 2011.

[9] E. Yılmaz, H. Baltas, E. Kırıs, I. Ustabas, U. Cevik, and A. M. El-Khayatt, "Gamma ray and neutron shielding properties of some concrete materials," Annals of Nuclear Energy, vol. 49, pp. 303-312, 2011.

[10] O. Gencel, A. Bozkurt, E. Kam, and T. Korkut, "Determination and calculation of gamma and neutron shielding characteristics of concretes containing different hematite proportions," Annals of Nuclear Energy, vol. 38, pp. 2719-2723, 2011.
[11] C. E. Acevedo and M. G. Serrato, "Determining the effects of radiation on aging concrete structures of nuclear reactors - 10243," presented at WM2010 Conference, Phoenix. AZ, March 2010.

[12] O. Gencel, W. Brostow, C, Ozel, and M. Filiz, "An investigation on the concrete properties containing colemanite," International Journal of Physical Sciences, vol. 5, pp. 216-225, 2010.

[13] M. Mahdy, P. R. S. Speare, and A. H. Abdel-Reheem, "Shielding properties of heavyweight, high strength concrete," presented at $2^{\text {nd }}$ Material Specialty Conference of the Canadian Society for Civil Engineering, June 5-8, 2002.

[14] C. M. Lee, Y. H. Lee, and K. J. Lee, "Cracking effect on gamma-ray shielding performance in concrete structure," Progress in Nuclear Energy, vol. 49, pp. 303-312, 2007.

[15] A. H. Bakhsh, "Engineering geological assessment of local high density aggregates for neutrons and gamma rays shielding," Ph.D. dissertation, Dept. Eng. Geo., King Abdulaziz University, Jeddah, KSA, 2001.

[16] F. Demir, G. Budak, R. Sahin, A. Karabulut, M. Oltulu, K. Serifoglu, and A. Und, "Radiation transmission of heavyweight- and normal-weight concretes containing colemanite for $6 \mathrm{MV}$ and $18 \mathrm{MV}$ X-rays using linear accelerator," Annals of Nuclear Energy, vol. 37, pp. 339-344, 2010.

[17] I. Akkurt, C. Basyigit, S. Kilincarslan, B. Mavi, and A. Akkurt, "Radiation shielding of concretes containing different aggregates," Cement \& Concrete Composite, vol. 28, pp. 153-157, 2006.

[18] I. I. Bashter, A. E. Abdo, and M. S. Abdel-Azim, "Magnetite ores with steel or basalt for concrete radiation shielding," Japanese Journal of Applied Physics Part1, vol. 36, pp. 3692-3696, 1997.

[19] I. I. Bashter, "Calculation of radiation attenuation coefficients for shielding concretes," Annals of Nuclear Energy, vol. 24, pp. 1389-1401, 1997.

[20] I. I. Bashter, A. S. Makarious, and A. E. Abdo, "Investigation of hematite-serpentine and ilmenite-limonite concretes for reactor radiation shielding," Annals of Nuclear Energy, vol. 23, pp. 65-71, 1996a.

[21] A. S. Mollah, G. U. Ahmad, and S. R. Husain, "Measurements of neutron shielding properties of heavyweight concretes using a Cf-252 source," Nuclear Engineering and Design, vol. 135, pp. 321-325, 1992.

[22] NISTIR 5632. (July 2004). Tables of X-Ray Mass Attenuation Coefficients and Mass Energy-Absorption Coefficients from $1 \mathrm{keV}$ to $20 \mathrm{MeV}$ for Elements $Z=1$ to 92 and 48 Additional Substances of Dosimetric Interest. National Institute of Standard and Technology, Physical Measurements Laboratory. [Online]. Available: http://www.nist.gov/pml/data/xraycoef/index.cfm.

[23] Guide for Selecting Proportions for High-Strength Concrete Using Portland Cement and Other Cementitious Materials, ACI 211.4R.-2008.

[24] Standard Specification for Portland Cement, American Society for Testing and Materials, ASTM C150 / C150M - 12, 1999.

[25] Standard Specification for Silica Fumes, American Society for Testing and Materials, ASTM C 1240-05, 1997.

[26] Standard Specification for Chemical Admixtures for Concrete, ASTM C 494 C 494/C 494M - 99a, 1999.

[27] Standard Specification for Concrete Aggregates, American Society for Testing and Materials, ASTM C33 - 99a, 1999.

[28] Standard Test Method for Slump of Hydraulic-Cement Concrete. American Society for Testing and Materials, ASTM C143 / C143M $12,1999$.

[29] Handbook of Radioactivity Analysis, Academic Press, California, M. F. L'Annunziata, 1998, p. 50.

[30] Standard Test Method for Compressive Strength of Cylindrical Concrete Specimens. American Society for Testing and Materials, ASTM C39 / C39M - 12a, 1999.

[31] I. Akkurt, C. Basyigit, S. Kilincarslan, and B. Mavi, "The shielding of $\gamma$-rays by concretes produced with barite," Progress in Nuclear Energy, vol. 46, pp. 1-11, 2005.

[32] S. Remzi, P. Recep, I. Orhan, and C. Cafer, "Determination of transmission factors of concretes with different water/cement ratio, curing condition, and dosage of cement and air entraining agent," Annals of Nuclear Energy, vol. 38, pp. 1505 - 1511, 2011.

[33] D. R. Ochbelagh, H. G. Mosavinejad, M. Molaei, S. Azimkhani, and M. Khodadoost, "Effect of low-dose gamma-radiation on concrete during solidification," International Journal of the Physical Sciences, vol. 5, pp. 1496-1500, September 2010. 
[34] D. Rezaei-Ochbelagh, H. Gasemzadeh Mosavinejad, M. Molaei, S. Azimkhani, and M. Khodadoost, "Effect of low-dose gamma-radiation on concrete during solidification," Internat. J. Phys. Sci., vol. 5, pp. 1496-1500, 2010.

[35] S. Glasstone and A. Sesonske, Nuclear Reactor Engineering, Library of congress, United States 1981, ch. 2, pp. 38-122.

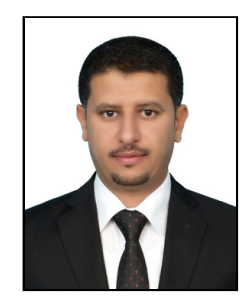

Mohammed M. Al-Humaiqani was born in Yemen, 1981. He received his BS.c in civil engineering from governmental Aden University, 2007. Today he is MSc student in structural engineering at King Saud University.

His research interest lies in development of concrete especially for energy structures, high strength concrete, and corrosion of steel reinforced concrete studies. He has authored 6 publications.
Ahmed B. Shuraim was born in Saudi Arabia, 1958. He received his Ph.D from the University of Michigan, Ann Arbor, Michigan in 1990. He is professor of Structural Engineering, Department of Civil Engineering, College of Engineering, King Saud University. He has carried out pertinent research and development activities in the areas of concrete technology and concrete construction as well as earthquake engineering and numerical modeling. He has done extensive numerical modeling using nonlinear finite elements programs such as ABAQUS as well as pushover applications using SAP2000. Dr. Shuraim has published extensively in the area of structural engineering and mechanics. His articles have been published in many of the premier journals of his field.

Raja Rizwan Hussain was born in Kuwait, 1978. He received his PhD and M.Sc. in Civil Engineering from the University of Tokyo, Japan. He is assistant professor in CoE-CRT, Department of Civil Engineering, College of Engineering, King Saud University. He has authored over 100 publications and has received several awards and prizes. His research interest lies in the corrosion of steel reinforced concrete. 